\title{
Endovascular total arch replacement techniques and early results
}

\author{
Vladimir Makaloski, Nikolaos Tsilimparis, Fiona Rohlffs, Franziska Heidemann, Eike Sebastian Debus, \\ Tilo Kölbel
}

Department of Vascular Medicine, German Aortic Center, University Heart Center Hamburg-Eppendorf, Hamburg, Germany

Correspondence to: Vladimir Makaloski, MD. Department of Vascular Medicine, German Aortic Centre, University Heart Center Hamburg-Eppendorf, Martinistraße 52, 20246 Hamburg, Germany. Email: vladimir.makaloski@insel.ch.

\begin{abstract}
During the last 20 years, a clear shift has been observed towards thoracic endovascular aortic repair for different aortic pathologies. However, total endovascular repair of the aortic arch remains technically demanding. Simultaneous perfusion of all supra-aortic arteries without longer cerebral ischemia time, whilst trying to avoid cerebral embolization, labels endovascular aortic arch repair with highest level of technical difficulty and surgical expertise. The aim of this article is to present an overview of the current technical options for endovascular aortic arch repair and their early results. Currently, early results are reported from four endovascular arch replacement techniques: hybrid repair, total endovascular approach, chimney grafts and insitu fenestration. The early results of these different arch replacement techniques are promising, especially the total arch replacement with custom-made fenestrated or branched stent-grafts. Long-term results are unknown, and larger series results and comparative studies are needed to determine safety and efficacy.
\end{abstract}

Keywords: Endovascular; arch replacement; early results

Submitted Feb 18, 2018. Accepted for publication Mar 23, 2018.

doi: $10.21037 /$ acs.2018.04.02

View this article at: http://dx.doi.org/10.21037/acs.2018.04.02

\section{Introduction}

During the last 20 years, a clear shift has been observed towards thoracic endovascular aortic repair (TEVAR) for different aortic pathologies. TEVAR is accepted as firstline treatment of thoracic aortic aneurysm, blunt traumatic aortic injury and complicated type B aortic dissection, including endovascular coverage of the distal aortic arch (zone 2 and 3) (1-3). However, the treatment of aortic arch pathologies is still predominantly performed by open repair via sternotomy, if no appropriate landing zones exist distal to zone 0 . Despite significant surgical, technical and anesthesiological developments in recent decades, open aortic arch repair still has high mortality and morbidity (4). De Rango et al. reported $14 \%$ of 30-day mortality rate in patients with open aortic arch repair compared with $8 \%$ of endovascular aortic arch repair (4). Every open aortic arch repair requires deep hypothermal circulatory arrest (DHCA) with the use of ante- or retrograde selective cerebral perfusion. Although antegrade selective cerebral perfusion reduces cerebral ischemia, the risk of overt stroke with permanent neurologic dysfunction after DHCA stays at $5 \%(5)$. In younger patients, and especially in patients with genetic aortic syndromes, open aortic arch repair is the preferred choice of treatment $(6,7)$. Recently, successful total endovascular aortic arch repair involving the zones 0 have been reported (8-10). The aim of this article is to present an overview of the current technical options for total endovascular aortic arch repair and their early results.

\section{Technical challenges}

Total endovascular aortic arch repair is technically demanding. Simultaneous perfusion of all supra-aortic arteries without longer cerebral ischemia time, whilst trying to avoid cerebral embolization, labels endovascular aortic arch repair with highest level of technical difficulty and surgical expertise. Despite sufficient anticoagulation with heparin, manipulation with endovascular armamentarium in the aortic arch can lead to cerebral embolisation, acute arm ischemia and/or paraplegia. There is risk of stent-graft dislocation ending with potential coverage and consecutive 


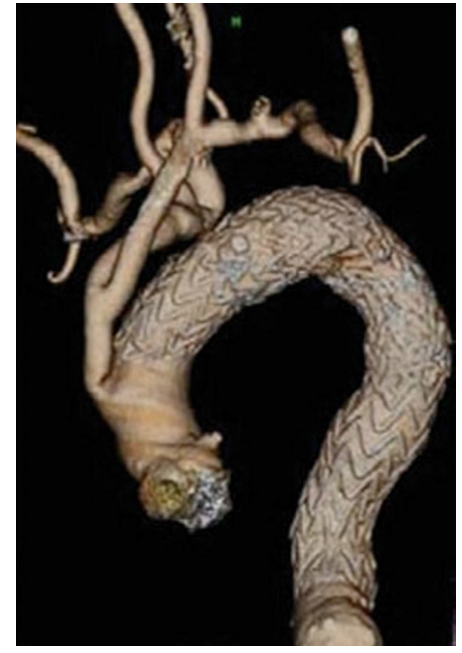

Figure 1 Postoperative 3D-reconstruction after total aortic arch debranching with ascending-brachiocephalic trunk bypass and transposition of the LCCA and LSA followed by TEVAR in landing zone 0. LCCA, left common carotid artery; TEVAR, thoracic endovascular aortic repair; LSA, left subclavian artery.

ischemia of supra-aortic vessels. Special mechanical features are required from the stent-graft: due to proximity of the landing zone to the left ventricle with high systolic blood pressure, windsocketing, material fatigue, stent fracture, migration or collapse can occur. At the same time, the stentgraft needs to adapt to the curvature of the aortic arch, thus allowing complete sealing and avoiding endoleaks. Large bore femoral access is required in order to deliver the stentgraft to the aortic arch. Bigger sheaths and thoracic stentgrafts have higher risk for access complication compared with regular endovascular abdominal aortic repair (11).

\section{Hybrid approach}

The goal of the hybrid approach is to create a sufficient landing zone in the aortic arch or the ascending aorta. In general, a hybrid approach is defined as debranching of one or more supra-aortic vessel in order to reduce the number of aortic arch vessels, thus simplifying the exclusion of the arch pathology with a tubular stent-graft (Figure 1). Transposition of the left subclavian artery (LSA) in the left common carotid artery (LCCA), or LCCA-LSA bypass with additional TEVAR, are well-accepted strategies for treatment of acute type B dissection or proximal descending aneurysm $(12,13)$.

A diversity of hybrid techniques in treatment of aortic arch pathologies have been published $(12,14-18)$. These include ascending-carotid or ascending-brachiocephalic trunk (BCT) bypass, followed by implantation of commercial off-theshelf thoracic stent-graft in the aortic arch or ascending aorta. These types of debranching require sternotomy. In a meta-analysis of 195 patients, Antoniou et al. demonstrated high rates of morbidity (21\%) and mortality (9\%), as well an endoleak rate of $9 \%$ and stroke rate of 7\% (19). Aortic arch pathologies requiring stent-grafts landing in the proximal aortic arch (zone 0 and 1 ) have higher stroke rate and rate of retrograde type A aortic dissection, compared with landing in the distal aortic arch (zone 2 and 3) (13).

\section{Endovascular approach (fenestrated and branched stent-grafts)}

The introduction of fenestrated and branched stent-grafts in the visceral aortic segment in the late 1990's revolutionized endovascular aortic repair. Total endovascular approach of different aortic arch pathologies with fenestrated or branched stent-grafts became attractive. Inoue et al. and Chuter et al. were the pioneers using branched stentgrafts for endovascular repair of aortic arch aneurysm and dissection (20-22). For total endovascular aortic arch repair, multiple access vessels (both brachial, femoral arteries and common carotid arteries) were used. Additional debranching of the LSA facilitates the completion of the treatment with only two branches or fenestrations.

Several companies aim for a "universal" off-the-shelf arch branch stent-graft. However, the diversity of anatomical varieties limits the applicability of such a stent-graft. The personalized "custom-made" production of an aortic arch stent-graft consisting of fenestrations, branches and scallops is currently the most acceptable treatment option for total endovascular aortic arch repair. The major disadvantage of all custom-made branched and fenestrated stent-grafts is the long waiting and production time of up to 3 months. Currently offered custom-made fenestrated and branched stent-grafts for the arch are described in this chapter.

\section{Inner branched device (Zenith Arch Endograft) by Cook Medical (Bloomington, IN, USA)}

This stent-graft is a custom-made device with two inner side branches for the BCT and the LCCA, designed according to patient's anatomy. Depending on size, the device is loaded either in a 22-Fr or 24-Fr hydrophilic sheath. The sheath is precurved in order to facilitate progression and self-alignment 

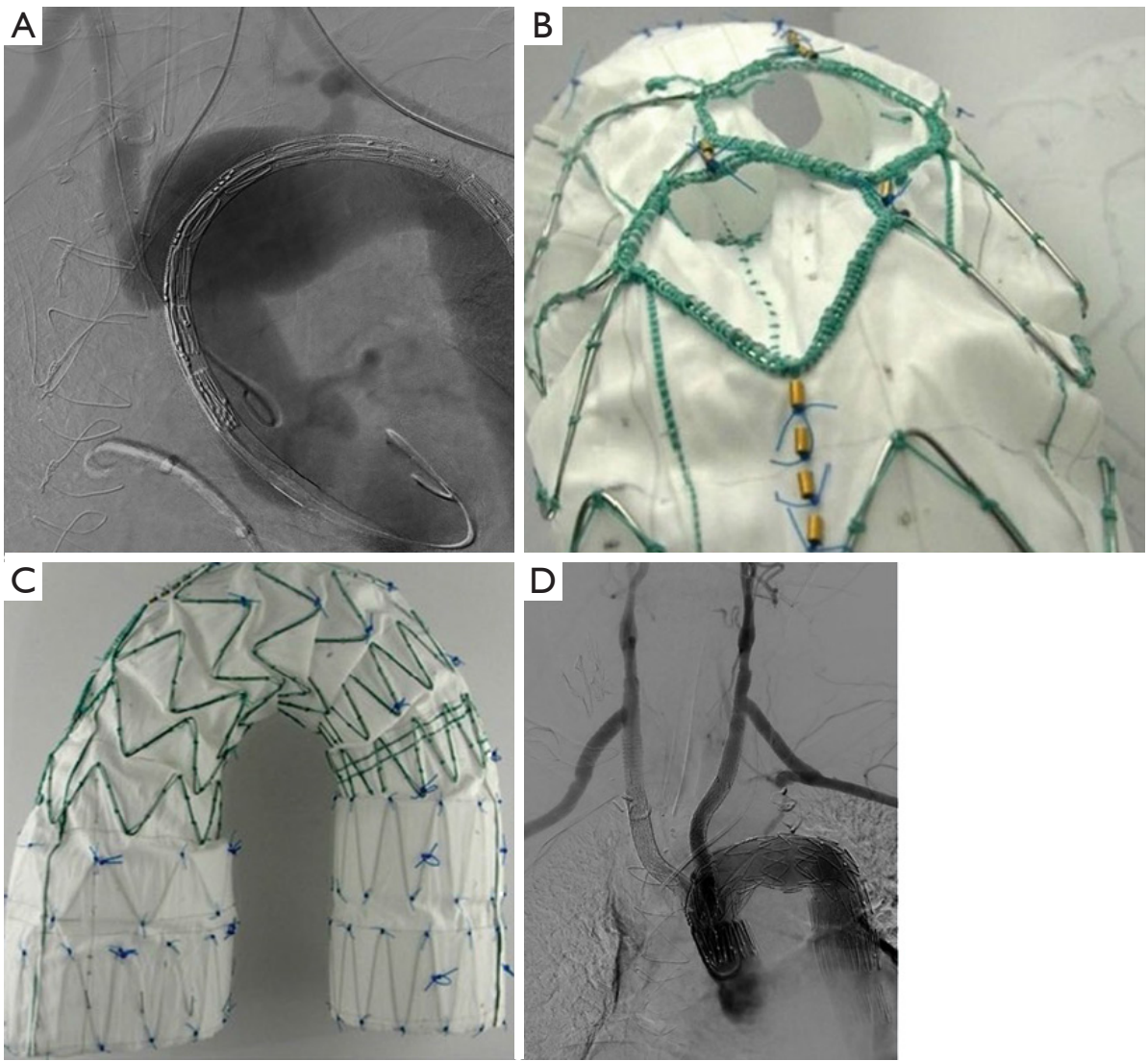

Figure 2 Double inner-branch Zenith arch endograft. (A) Intraoperative angiography of an aortic arch aneurysm after open ascending repair with undeployed double-branched stent-graft in the arch; (B,C) double inner-branch Zenith Arch Endograft; (D) completion angiography with bilateral carotid interposition graft and bilateral carotid-subclavian bypass.

in the aortic arch. Both BCT and LCCA are connected in a retrograde fashion with the two inner branches within the stent-graft (Figure 2). The bridging stent-graft for the BCT is manufactured with low profile graft fabric and loaded into a short 14-Fr Flexor delivery system (Cook Medical, Bloomington, IN, USA). For the LCCA, a commercially available self-expanding covered stent, Fluency (CR Bard, Murray Hill, NJ, USA) or Viabahn (WL Gore, Flagstaff, AZ, USA) are used as a bridging component.

Haulon et al. published in 2014 the first larger experience with the double inner-branch Zenith Arch Endograft (23). This multicenter study reports the early results after treatment of 38 patients and demonstrated a technical success rate of $84 \%$ with 30 -day mortality rate of $13 \%$. No aneurysm-related deaths during a follow-up period of 12 months were observed. The learning curve significantly influenced the outcome: after the first 10 patients, a $30 \%$ mortality rate was observed, whereas only $7 \%$ of the later
28 patients died thereafter (23). Another multicenter study with 27 patients, including 12 patients from our department, showed zero mortality and increase of the technical success rate to $100 \%$ (8). The perioperative stroke rate decreased as well from $16 \%$ to $11 \%$ compared with the previously published report $(8,23)$.

LCCA-LSA bypass prior to implantation of the branched arch device is usually performed in a staged approach. Recent technical development allows for complete endovascular aortic arch treatment without any additional cervical debranching. Successful treatment of three patients treated with arch stent-graft containing three inner branches was reported very recently (24).

\section{Fenestrated custom-made device by Cook Medical (Bloomington, IN, USA)}

This custom-made stent-graft is constructed with either a 
single fenestration and a scallop, or a single fenestration or a single scallop. All fenestrated stent-grafts are manufactured with a preloaded wire and catheter running through the fenestration, or the scallop with constraining wires. Usually, the seal zone of these stent-grafts is located in the mid-arch, depending on the vessels targeted. In case the fenestration is aimed for the LSA, a left-brachial through-and-through wire is used to safeguard the position of the fenestration. The fenestration is typically reinforced by a covered balloon expandable stent and other stents as needed. Fenestrated arch devices require less cervical debranching and addresses less target vessel compared with branched arch devices. Both fenestrated and branched arch devices are feasible for the treatment of aortic arch diseases in high-risk patients (25).

\section{Inoue stent-graft (PTMC Institute)}

This is a custom-made all-in-one stent-graft consisting of an aortic trunk and branch sections, which are sewn together. Both main body and branched section are constructed with a woven Dacron (Du Pont, Wilmington, DE, USA) polyester graft, on which extra flexible nickel titanium rings are placed for reinforcement and self-expandability . Additional Dacron cuffs are attached on both ends proximally and distally to facilitate the sealing between the graft and aortic inner wall. The main body and branch section are prepared separately from two pieces of Dacron grafts, with varying diameters in $2-\mathrm{mm}$ increments from 18 to $46 \mathrm{~mm}$ and from 8 to $20 \mathrm{~mm}$, respectively. Traction-wires are attached to the outer branches and snared from the target vessel for pulling and alignment of the branches into target vessel. Tazaki et al. published the biggest series of 89 patients treated with Inoue branched stent-graft reporting 100\% technical success, 16\% periprocedural stroke and freedom from aneurysm-related death of $93 \%$ at 5-year follow-up (26).

\section{Najuta fenestrated stent-graft (Kawasumi Laboratories, Inc.)}

The Najuta fenestrated stent-graft is a custom-made precurved and fenestrated stent-graft. There are seven different positioning patterns and three size patterns of fenestration ranging from $11.5 \mathrm{~mm} \times 13.0 \mathrm{~mm}$ to $16.0 \mathrm{~mm} \times 18.0 \mathrm{~mm}$, resulting with 64 patterns of stent frame and 21 patterns of fenestration configuration in total. These fenestrations are crossed by stent-struts and are not reinforced, so that no additional stenting of these fenestrations is possible. Iwakoshi et al. reported technical success rate of $91 \%$ using the Najuta stent-graft in 32 patients (27). Aneurysm-related rate and rate of freedom from secondary intervention at 3 years were $97 \%$ and $84 \%$, respectively $(27)$.

\section{Branched stent-graft by MicroPort Medical Co., Ltd.}

This custom-made branched stent-graft is constructed of woven polyester fabric sewn to self-expanding nitinol stents, without a proximal or distal bare stent. The delivery system consists of an outer 22-Fr sheath with a hydrophilic coating and an inner soft polyester fabric sheath . The aortic graft trunk and the branch section are folded individually, thus allowing their deployment consecutively, rather than simultaneously. A total of 53 branched stent-grafts were used in 51 patients with chronic aortic dissections involving the aortic arch (28). Lu et al. reported $100 \%$ technical success rate, no in-hospital stroke and one death because of retrograde type A dissection on the sixth postoperative day. During median follow-up of 44 months (range, 14-66 months) complete thrombosis of the false lumen in the descending aorta was observed in $92 \%$ (47/51) and partial thrombosis in 8\% (4/51) (28). No further deaths or stroke occurred during follow-up and no branch section of the stent-graft was kinked or occluded (28).

\section{Bolton arch branch and fenestrated device (Bolton Medical, Barcelona, Spain)}

The Bolton branched arch stent-graft is built on the Relay NBS platform using two parallel inner-branches and a proximal tip-capture. It is constructed of polyester fabric and nitinol stents. The branches are internal (referred to as anterior and posterior tunnels), both of which have 12-mm diameters and are usually not solely paired to either BCT or LCCA. The maximal length of this device is 270 $\mathrm{mm}$, meaning that these stent-grafts span the entire arch as a single device. With this length, any distal thoracic stentgraft can be mated in the descending aorta and not in the distal arch. Early experience in a small series collecting global experience showed $7 \%$ mortality and 20\% stroke rate (29). Similar to the Najuta device, a custom-made Bolton fenestrated stent-graft is available, without any option for additional stenting of the fenestration due to crossing stent-struts in the fenestrations.

\section{Alternative investigational stent-graft systems}

Recently, preliminary results of the first-in-human, early 

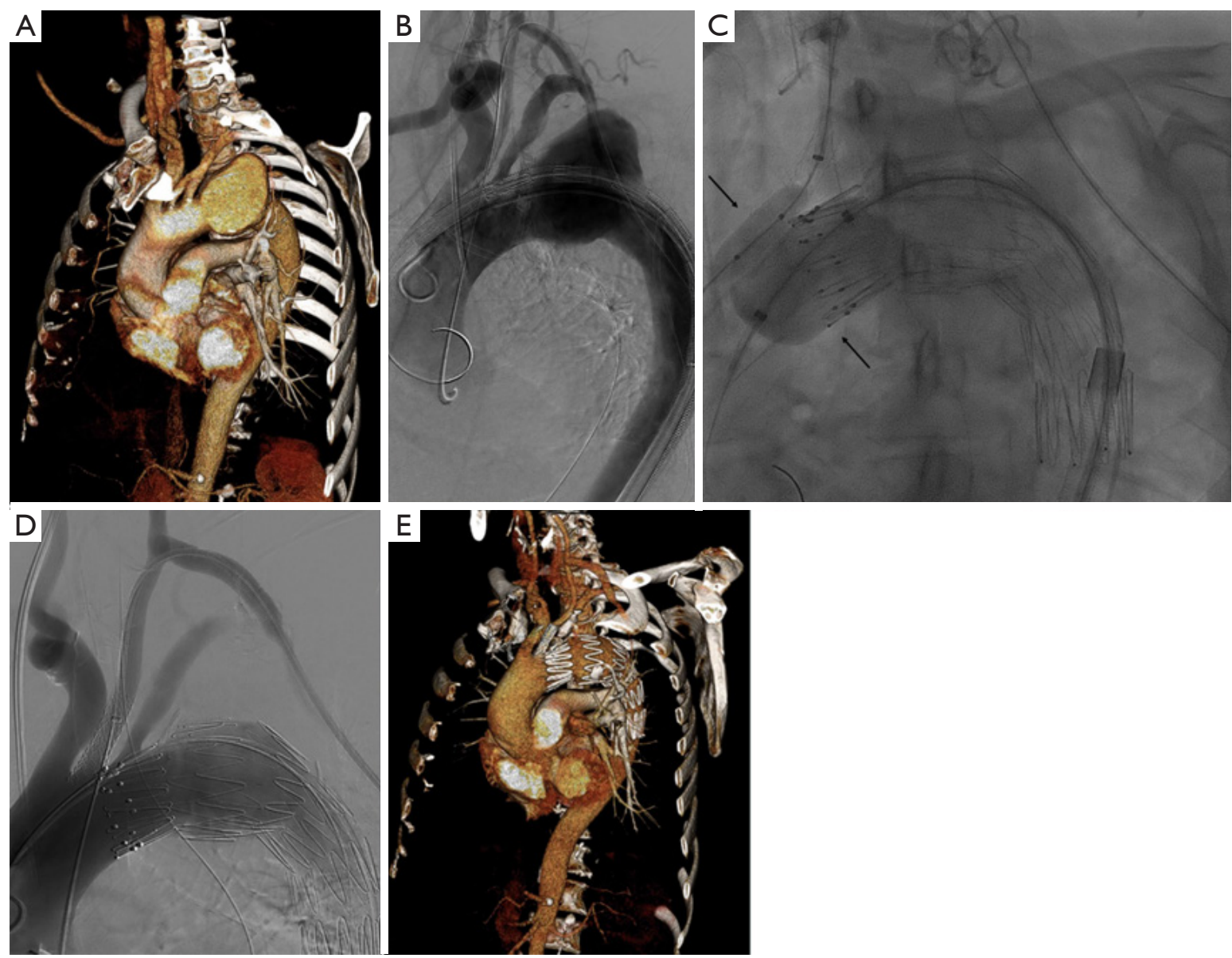

Figure 3 Chimney technique for aortic arch. (A) 3D-reconstruction of preoperative CT-angiography; (B) intraoperative angiography with undeployed thoracic stent-graft in the arch and covered stent in the LCCA; (C) balloon-molding in kissing-balloon technique (black arrows) of both chimney graft and thoracic stent-graft; (D) completion angiography after TEVAR, chimney graft in the LCCA and leftsided carotid-subclavian bypass, without plug in the LSA; (E) 3D-reconstruction of postoperative CT-angiography after TEVAR, chimney graft in the LCCA, vascular plug in the LSA and left-sided carotid-subclavian bypass. LCCA, left common carotid artery; TEVAR, thoracic endovascular aortic repair; LSA, left subclavian artery.

feasibility trials for two single-branched arch devices designed for zone 2 deployment have been reported. The Valiant Mona LSA Thoracic Stent Graft System (Medtronic, Santa Rosa, California, USA), based on the Valiant thoracic stent-graft platform, has been successfully deployed in nine patients with descending thoracic aortic aneurysms (30). No major and four minor strokes were observed during 30day follow-up (30). Midterm results are expected as patients are monitored at regular intervals to 5 years. There have been no reports of death, rupture, paraplegia, conversion or secondary endovascular procedure during follow-up (30). Similarly, Gore Thoracic Branch Endoprosthesis (WL Gore, Flagstaff, AZ, USA) based on the cTAG platform with a caudally-oriented internal branch, was used in 22 patients with distal arch aneurysms (31). Technical success rates of $100 \%$, without 30-day death, stroke or permanent paraplegia were reported (31). These novel single-branched arch stentgrafts can be successfully used for total endovascular repair of distal zone 2 aortic arch aneurysms. More proximal arch zones would require additional surgical revascularization of indispensable arch branches as indicated.

\section{Chimney grafts}

This technique is based on the implantation of several parallel covered stents and stent-grafts (Figure 3). Originally 

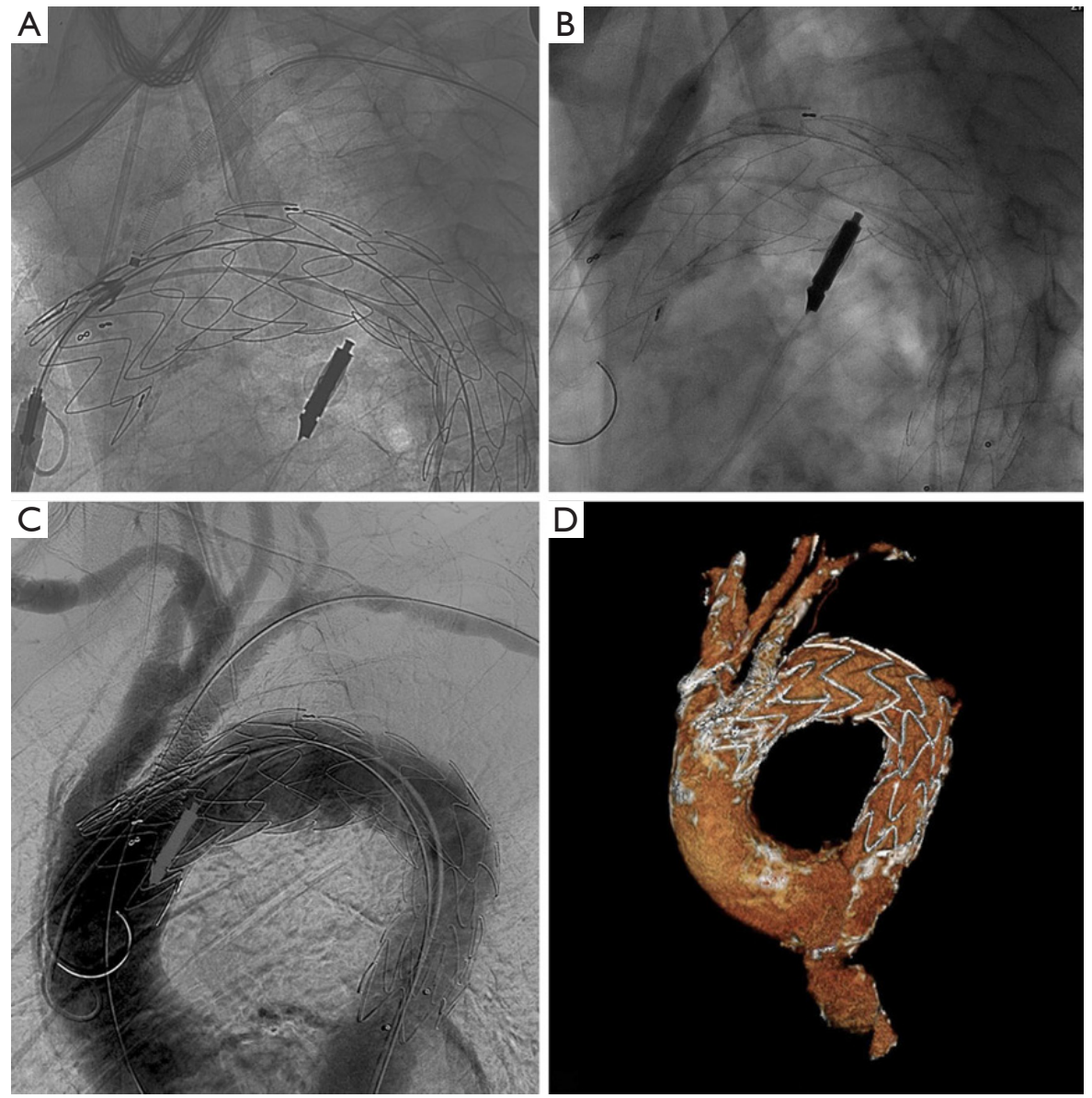

Figure 4 In-situ fenestration for aortic arch vessels. (A) Intraoperative fluoroscopy with in-situ fenestration of the thoracic stent-graft; (B) dilation of the fenestration with non-compliant balloon; (C) completion angiography; (D) 3D-reconstruction of postoperative CTangiography after TEVAR with in-situ fenestration and stenting of the LSA. TEVAR, thoracic endovascular aortic repair; LSA, left subclavian artery.

planned for the preservation of the LSA, the chimney grafts are also used for proximal extension of the landing zone in the aortic arch as well as a potential "bail-out" strategy after unintentional coverage of supra-aortic vessel (32). Moulakakis et al. published a meta-analysis of 136 patients with chimney grafts in the aortic arch, reporting an endoleak rate of $11 \%$ and $8 \%$ for type Ia and type II endoleak, respectively (33). A stroke rate of $4 \%$ was observed (31). Similarly, another meta-analysis of 94 patients with 101 chimney grafts in the aortic arch reported a perioperative mortality rate of $3 \%$, stroke rate of $5 \%$ and endoleak rate of $18 \%$ (of those most frequently type Ia with 6\%) (34). The latest meta-analysis published in 2015 analysing the results of 364 chimney grafts in the aortic arch reported similar endoleak rates of $11 \%$, with reduction of the stroke rate to $1.7 \%(35)$.

\section{In-situ fenestration}

This technique has been used as a bail-out option after unintentional coverage of supra-aortic vessels as well as a planned technique to revascularize arch vessels (36-39). With the help of a catheter-driven needle, laser or radiofrequency, ante- or retrograde fenestration in the thoracic stent-graft is created and connected with a covered stent allowing antegrade perfusion (Figure 4). Redlinger et al. published the largest series up-to-date with 22 patients undergoing laser fenestration of the LSA after emergency TEVAR for different pathologies, intentionally covering the LSA-origin (36). No fenestration-associated 
morbidity and in-hospital mortality of $4 \%$ were found. After 11 months of follow-up, all LSA stents were patent (36). Two other smaller series showed similar early midterm results concerning mortality, stroke and endoleak $(40,41)$. Longer patency results after in-situ fenestration have to be awaited.

\section{Conclusions}

Endovascular total arch replacement technologies are characterized by rapid development and improvement of the material and methods. Open repair still stands as the first-line treatment, but the endovascular total arch replacement is a valuable option for a patient who is highrisk or unfit for open repair. The early results of different arch replacement technologies are promising, especially the total arch replacement with custom-made fenestrated or branched stent-grafts. Long-term results are unknown, and larger series results and comparative studies are needed to determine safety and efficacy.

\section{Acknowledgements}

None.

\section{Footnote}

Conflicts of Interest: Tilo Kölbel acts as a proctor for, has intellectual property with Cook Medical and receives travel and research grants from Cook Medical. The other authors have no conflicts of interest to declare.

\section{References}

1. Ishimaru S. Endografting of the aortic arch. J Endovasc Ther 2004;11 Suppl 2:II62-71.

2. Cheng D, Martin J, Shennib H, et al. Endovascular aortic repair versus open surgical repair for descending thoracic aortic disease a systematic review and meta-analysis of comparative studies. J Am Coll Cardiol 2010;55:986-1001.

3. Grabenwöger M, Alfonso F, Bachet J, et al. Thoracic Endovascular Aortic Repair (TEVAR) for the treatment of aortic diseases: a position statement from the European Association for Cardio-Thoracic Surgery (EACTS) and the European Society of Cardiology (ESC), in collaboration with the European Association of Percutaneous Cardiovascular Interventions (EAPCI). Eur J Cardiothorac Surg 2012;42:17-24.
4. De Rango P, Ferrer C, Coscarella C, et al. Contemporary comparison of aortic arch repair by endovascular and open surgical reconstructions. J Vasc Surg 2015;61:339-46.

5. Cefarelli M, Murana G, Surace GG, et al. Elective Aortic Arch Repair: Factors Influencing Neurologic Outcome in 791 Patients. Ann Thorac Surg 2017;104:2016-23.

6. Erbel R, Aboyans V, Boileau C, et al. 2014 ESC Guidelines on the diagnosis and treatment of aortic diseases: Document covering acute and chronic aortic diseases of the thoracic and abdominal aorta of the adult. The Task Force for the Diagnosis and Treatment of Aortic Diseases of the European Society of Cardiology (ESC). Eur Heart J 2014;35:2873-926.

7. Hiratzka LF, Bakris GL, Beckman JA, et al. 2010 ACCF/AHA/AATS/ACR/ASA/SCA/SCAI/SIR/STS/ SVM guidelines for the diagnosis and management of patients with Thoracic Aortic Disease: a report of the American College of Cardiology Foundation/American Heart Association Task Force on Practice Guidelines, American Association for Thoracic Surgery, American College of Radiology, American Stroke Association, Society of Cardiovascular Anesthesiologists, Society for Cardiovascular Angiography and Interventions, Society of Interventional Radiology, Society of Thoracic Surgeons, and Society for Vascular Medicine. Circulation 2010;121:e266-369. Erratum in: Circulation 2010;122:e410.

8. Spear R, Haulon S, Ohki T, et al. Editor's choice - subsequent results for arch aneurysm repair with inner branched endografts. Eur J Vasc Endovasc Surg 2016;51:380-5.

9. Tsilimparis N, Debus ES, Oderich GS, et al. International experience with endovascular therapy of the ascending aorta with a dedicated endograft. J Vasc Surg 2016;63:1476-82.

10. Ye C, Chang G, Li S, et al. Endovascular stent-graft treatment for Stanford type A aortic dissection. Eur J Vasc Endovasc Surg 2011;42:787-94.

11. Hu G, Chen B, Fu W, et al. Predictors and Treatments of Proglide-Related Complications in Percutaneous Endovascular Aortic Repair. PLoS One 2015;10:e0123739.

12. Antoniou GA, Mireskandari M, Bicknell CD, et al. Hybrid repair of the aortic arch in patients with extensive aortic disease. Eur J Vasc Endovasc Surg 2010;40:715-21.

13. Chiesa R, Melissano G, Tshomba Y, et al. Ten years of endovascular aortic arch repair. J Endovasc Ther 2010;17:1-11.

14. Appoo JJ, Herget EJ, Pozeg ZI, et al. Midterm results of 
endovascular stent grafts in the proximal aortic arch (zone 0): an imaging perspective. Can J Cardiol 2015;31:731-7.

15. Czerny M, Weigang E, Sodeck G, et al. Targeting landing zone 0 by total arch rerouting and TEVAR: midterm results of a transcontinental registry. Ann Thorac Surg 2012;94:84-9.

16. Gelpi G, Vanelli P, Mangini A, et al. Hybrid aortic arch repair procedure: reinforcement of the aorta for a safe anddurable landingzone. Eur J Vasc Endovasc Surg 2010;40:709-14.

17. Lotfi S, Clough RE, Ali T, et al. Hybrid repair of complex thoracic aortic arch pathology: long-term outcomes of extra-anatomic bypass grafting of the supra-aortic trunk. Cardiovasc Intervent Radiol 2013;36:46-55.

18. Vallejo N, Rodriguez-Lopez JA, Heidari P, et al. Hybrid repair of thoracic aortic lesions for zone 0 and 1 in highrisk patients. J Vasc Surg 2012;55:318-25.

19. Antoniou GA, El Sakka K, Hamady M, et al. Hybrid treatment of complex aortic arch disease with supra-aortic debranching and endovascular stent graft repair. Eur J Vasc Endovasc Surg 2010;39:683-90.

20. Inoue K, Hosokawa H, Iwase T, et al. Aortic arch reconstruction by transluminally placed endovascular branched stent graft. Circulation 1999;100:II316-21.

21. Chuter TA, Schneider DB, Reilly LM, et al. Modular branched stent graft for endovascular repair of aortic arch aneurysm and dissection. J Vasc Surg 2003;38:859-63.

22. Chuter TA, Schneider DB. Endovascular repair of the aortic arch. Perspect Vasc Surg Endovasc Ther 2007;19:188-92.

23. Haulon S, Greenberg RK, Spear R, et al. Global experience with an inner branched arch endograft. J Thorac Cardiovasc Surg 2014;148:1709-16.

24. Spear R, Clough RE, Fabre D, et al. Total Endovascular Treatment of Aortic Arch Disease Using an Arch Endograft With 3 Inner Branches. J Endovasc Ther 2017;24:534-8.

25. Tsilimparis N, Debus ES, von Kodolitsch Y, et al. Branched versus fenestrated endografts for endovas $\neg$ cular repair of aortic arch lesions. J Vasc Surg 2016;64:592-9.

26. Tazaki J, Inoue K, Higami H, et al. Thoracic endovascular aortic repair with branched Inoue Stent Graft for arch aortic aneurysms. J Vasc Surg 2017;66:1340-8.e5.

27. Iwakoshi S, Ichihashi S, Itoh H, et al. Clinical outcomes of thoracic endovascular aneurysm repair using commercially available fenestrated stent graft (Najuta endograft). J Vasc Surg 2015;62:1473-8.

28. Lu Q, Feng J, Zhou J, et al. Endovascular repair by customized branched stent-graft: A promising treatment for chronic aortic dissection involving the arch branches. J Thorac Cardiovasc Surg 2015;150:1631-8.e5.

29. Czerny M, Rylski B, Morlock J, et al. Orthotopic branched endovascular aortic arch repair in patients who cannot undergo classical surgery. Eur J Cardiothorac Surg 2018;53:1007-12.

30. Roselli EE, Arko FR 3rd, Thompson MM, et al. Results of the Valiant Mona LSA early feasibility study for descending thoracic aneurysms. J Vasc Surg 2015;62:146571.e3.

31. Patel HJ, Dake MD, Bavaria JE, et al. Branched Endovascular Therapy of the Distal Aortic Arch: Preliminary Results of the Feasibility Multicenter Trial of the Gore Thoracic Branch Endoprosthesis. Ann Thorac Surg 2016;102:1190-8.

32. Mangialardi N, Serrao E, Kasemi H, et al. Chimney technique for aortic arch pathologies: an 11-year singlecenter experience. J Endovasc Ther 2014;21:312-23.

33. Moulakakis KG, Mylonas SN, Dalainas I, et al. The chimney-graft technique for preserving supraaortic branches: a review. Ann Cardiothorac Surg 2013;2:339-46.

34. Hogendoorn W, Schlosser FJ, Moll FL, et al. Thoracic endovascular aortic repair with the chimney graft technique. J Vasc Surg 2013;58:502-11.

35. Lindblad B, Bin Jabr A, Holst J, et al. Chimney grafts in aortic stent grafting: hazardous or useful technique? systematic review of current data. Eur J Vasc Endovasc Surg 2015;50:722-31.

36. Redlinger RE Jr, Ahanchi SS, Panneton JM. In situ laser fenestration during emergent thoracic endovascular aortic repair is an effective method for left subclavian artery revascularization. J Vasc Surg 2013;58:1171-7.

37. Ahanchi SS, Almaroof B, Stout CL, et al. In situ laser fenestration for revascularization of the left subclavian artery during emergent thoracic endovascular aortic repair. J Endovasc Ther 2012;19:226-30.

38. Murphy EH, Dimaio JM, Dean W, et al. Endovascular repair of acute traumatic thoracic aortic transection with laser-assisted in-situ fenestration of a stent-graft covering the left subclavian artery. J Endovasc Ther 2009;16:457-63.

39. Tsilimparis N, Debus ES, Wipper S, et al. Proximal thoracic endograft displacement rescued by balloonassisted pull-back, external shunting, and in situ fenestration of the left carotid artery. J Vasc Surg 2016;63:815-8.

40. Tse LW, Lindsay TF, Roche-Nagle G, et al. 
Radiofrequency in situ fenestration for aortic arch vessels during thoracic endovascular repair. J Endovasc Ther 2015;22:116-21.

41. Katada Y, Kondo S, Tsuboi E, et al. Endovascular total arch repair using in situ fenestration for arch aneurysm and chronic type A dissection. Ann Thorac Surg 2016;101:625-30.

Cite this article as: Makaloski V, Tsilimparis N, Rohlffs F, Heidemann F, Debus ES, Kölbel T. Endovascular total arch replacement techniques and early results. Ann Cardiothorac Surg 2018;7(3):380-388. doi: 10.21037/acs.2018.04.02 